\title{
Retraction
}

\section{Retracted: Fructose Diet-Induced Skin Collagen Abnormalities Are Prevented by Lipoic Acid}

\section{Journal of Diabetes Research}

Received 28 February 2022; Accepted 28 February 2022; Published 19 April 2022

Copyright (c) 2022. This is an open access article distributed under the Creative Commons Attribution License, which permits unrestricted use, distribution, and reproduction in any medium, provided the original work is properly cited.

Journal of Diabetes Research

Journal of Diabetes Research has retracted the article titled "Fructose Diet-Induced Skin Collagen Abnormalities Are Prevented by Lipoic Acid," [1], due to concerns with images contained within the manuscript as noted on PubPeer [2]. There appears to be a duplication of several bands both within and between the SDS gel patterns in Figures 3(a) and $3(\mathrm{~b})$. Additionally, there appears to be multiple duplications and inconsistencies in the background of the gels within and between both figures.

The authors responded to explain that the similarities between the gels could be because the same set of collagen proteins were screened, but in different fractions. The running patterns of enriched protein bands and residual protein bands are not discrepant within the lane, which the authors considers confirmation that these are accurate images. Additionally, the authors noted that most of the similarities pointed out are artefacts identified by software when the contrast of the picture is altered, and researchers routinely performing SDS page and Western blotting would agree that such things occur commonly.

The authors were unable to provide the original images, which they state is due to the length of time since the experiment was conducted, and were unable to satisfy the concerns of the editorial board. The article is therefore being retracted due to concerns with the reliability of the data. The authors agree to the retraction.

\section{References}

[1] V. Thirunavukkarasu, A. T. Anitha Nandhini, and C. V. Anuradha, "Fructose Diet-Induced Skin Collagen Abnormalities are Prevented by Lipoic Acid," Journal of Diabetes Research, vol. 5, 8 pages, 2004.

[2] E. M. Bik, PubPeer, November 2019. https://pubpeer.com/ publications/8E18CF1AD7A63D9B3410635F158781. 


\title{
Fructose Diet-Induced Skin Collagen Abnormalities Are Prevented by Lipoic Acid
}

\author{
V. Thirunavukkarasu, A. T. Anitha Nandhini, and C. V. Anuradha \\ Department of Biochemistry, Faculty of Science, Annamalai University, Annamalai Nagar, India
}

Nonenzymatic glycation of proteins, leading to chemical modification and cross-linking are of importance in the pathology of diabetic complications. We studied the effect of $\alpha$-lipoic acid (LA) on the content and characteristics of the protein collagen from skin of high-fructose fed rats. The rats were divided into 4 groups of 6 each. Two groups of rats were fed with a high fructose diet $(60 \mathrm{~g} / 100 \mathrm{~g}$ diet $)$ and administered either LA (35 mg/kg b.w., i.p) (FRU+LA) or $0.2 \mathrm{ml}$ vehicle (saline) (FRU) for 45 days. The other 2 groups were fed with control diet containing starch $(60 \mathrm{~g} / 100 \mathrm{~g}$ diet) and administered either saline (CON) or lipoic acid $(\mathrm{CON}+\mathrm{LA})$. The rats were maintained for 45 days and then sacrificed. Plasma glucose, insulin, fructosamine, protein glycation, and blood glycated hemoglobin $\left(\mathrm{HbA}_{1} \mathrm{C}\right)$ were measured. Collagen was isolated from skin and the physicochemical properties of collagen were studied. Fructose administration caused accumulation of collagen in skin. Extensive cross-linking was evidenced by enhanced glycation and AGE-linked fluorescence. Increased peroxidation and changes in physicochemical properties such as shrinkage temperature, aldehyde content, solubililty pattern, susceptibility to denaturing agents were observed in fructose-fed rats. SDS gel pattern of collagen from these rats showed elevated $\beta$ component of type I collagen. These changes were alleviated by the simultaneous administration of LA. Administration of LA to fructose-fed rats had a positive influence on both quantitative and qualitative properties

Received 10 May 2004; accepted 9 July 2004.

The authors thank Dr. L. Suguna, Project Fellow, Bioproducts Laboratory, Central Leather Research Institute, Chennai, for her help in carrying out the electrophoresis of collagen samples.

Address correspondence to C. V. Anuradha, Department of Biochemistry, Faculty of Science, Annamalai University, Annamalai Nagar, Tamil Nadu-608 002, India. E-mail: cvaradha@ hotmail.com of collagen. The results suggest a mechanism for the ability of LA to delay diabetic complications.

Keywords Fructose Diet; Glycation; Collagen; Cross Linkage; Lipoic Acid

\section{INTRODUCTION}

Collagens form the major structural proteins of all connective tissues and the interstitial tissue of all parenchymal organs and contribute to the stability and structural integrity of tissues and organs. Collagens are centrally involved in the formation of the fibrillar and microfibrillar network of the extracellular matrix and basement membranes [1]. Among the 20 different collagens so far identified, type I collagen is the most abundant collagen which forms more than $90 \%$ of the organic mass of bone and is the major collagen of tendons, skin, ligaments, cornea, and many interstitial connective tissues [2].

Glycation (Maillard reaction) is a nonenzymatic binding reaction between proteins and glucose that leads to the formation of advanced glycation end products (AGE). Glycation could cause changes in the structural and functional properties of proteins and are of importance in the etiology of secondary complications in diabetes [3]. Collagen is a protein with slow turnover rate that contains several basic amino acids with free amino groups and is a strong candidate for extensive modification by glycation [4]. AGEs have been shown to be associated with structural alterations in collagen by forming cross-links between collagen fibers and this creates an increase in mechanical stiffness [5] and a decrease in susceptibility to enzymatic digestion [6]. The diabetes-associated changes in collagen function have been documented to be a biochemical link between persistent hyperglycemia and diabetic microvascular disease [7]. 
$\alpha$-Lipoic acid (LA) (1,2, dithiolane-3-pentanoic acid), a natural cofactor of mitochondrial dehydrogenases complexes, is a physiological constituent of mitochondrial membranes and an endogenous antioxidant. Four distinct antioxidant actions of LA have been observed including reactive oxygen species scavenging activity, capacity to regenerate endogenous antioxidants such as glutathione, vitamins $\mathrm{C}$ and $\mathrm{E}$, metal chelating activity, and repair of oxidized proteins $[8,9]$.

Dietary fructose has adverse effects on carbohydrate metabolism [10]. Fructose-rich diet induces insulin resistance, hyperinsulinemia, glucose intolerance, hypertriglyceridemia and hypertension in rats. Fructose feeding is frequently used as an animal model for insulin resistance. Fructose feeding has been shown to cause glycation and crosslinking of skin collagen in rats [10].

Positive influence of LA has been observed in studies involving high carbohydrate feeding. LA was found to prevent the rise in blood pressure and to improve insulin sensitivity in chronic glucose-fed [11] and fructose-fed rats [12]. However, no experimental data are available on the effect of LA on collagen structure and properties. The present study explores whether LA administration would prevent collagen accumulation in skin and would improve variables such as solubility, shrinkage temperature, glycation and fluorescence in high fructose-fed rats.

\section{MATERIALS AND METHODS}

Male Wistar rats of body weights of $150-170 \mathrm{~g}$ were obtained from the Central Animal House of Rajah Muthiah Medical College, Annamalai University. They were housed two per cage under $12 \mathrm{hr}$ - light and $12 \mathrm{hr}$ - dark cycle. The rats were fed during the acclimatization period of 10 days with a standard pellet diet (Karnataka State Agro Corporation Private Ltd., Agro, feeds division, Bangalore, India). The animals used in the present study were cared for in accordance with the principles and guidelines of the Institutional Animal Ethics Committee, Rajah Muthiah Medical College, Annamalai University, Annamalai Nagar.

\section{Animals and Treatment}

The animals were divided into 4 groups of 6 rats each.

Group 1: (CON):

received control diet and water ad libitum. $0.2 \mathrm{ml}$ of vehicle (saline) was given intraperitoneally daily.

Group 2: (FRU): received fructose-enriched diet and water ad libitum. $0.2 \mathrm{ml}$ of vehicle (saline) was given intraperitoneally daily.

Group 3: (FRU+LA): received fructose diet and administered with lipoic acid (35 mg/kg b.w) dissolved in saline by intraperitoneal injection once daily.

Group 4: $(\mathrm{CON}+\mathrm{LA})$ : received the control diet and were given lipoic acid ( $35 \mathrm{mg} / \mathrm{kg}$ b.w) in saline by intraperitoneal injection once daily.

The compositions of control and fructose diets are given in Table 1. The diets were prepared fresh daily. The animals were maintained in their respective groups for 45 days. Body weight changes were measured weekly. At the end of the experimental period the rats were sacrificed by cervical decapitation and blood was collected and processed for plasma separation. Skin was dissected from the dorsal side of the abdomen and removed of hairs. Glucose [13], fructosamine [14], and glycated protein levels [15] were measured in plasma, while glycated hemoglobin $\left(\mathrm{HbA}_{1} \mathrm{C}\right)$ was measured in blood [15]. Plasma insulin was estimated by the microparticle enzyme immuno assay method, using a reagent kit (Boehringer Manheim, Germany).

A weighed amount of fresh skin tissue (5g) was defatted with a chloroform:methanol (CM, 2:1) mixture and lyophilized. The lyophilized sample was hydrolysed with $6 \mathrm{~N} \mathrm{HCl}$ for $18 \mathrm{~h}$ at $110^{\circ} \mathrm{C}$. After hydrolysis the digested sample was evaporated to dryness, dissolved in water and hydroxyproline content was measured [16]. Total collagen content was determined by multiplying the hydroxyproline content determined by a factor 7.46. The extent of glycation was determined by the method of Rao and Pattabiraman [15] using concentrated sulphuric acid and $80 \%$ phenol.

TABLE 1

Composition of diet $(\mathrm{g} / 100 \mathrm{~g})$

\begin{tabular}{lcc}
\hline Ingredients & Control diet & High fructose diet \\
\hline Corn starch & 60 & - \\
Fructose & - & 60 \\
Casein (fat free) & 20 & 20 \\
Methionine & 0.7 & 0.7 \\
Groundnut oil & 5 & 5 \\
Wheat bran & 10.6 & 10.6 \\
Salt mixture* & 3.5 & 3.5 \\
Vitamin mixture $^{* *}$ & 0.2 & 0.2 \\
\hline
\end{tabular}

*The composition of mineral mix $(\mathrm{g} / \mathrm{Kg})-\mathrm{MgSO}_{4} 7 \mathrm{H}_{2} \mathrm{O}$ 30.5; NaCl-65.2; KCl-105.7; $\mathrm{KH}_{2} \mathrm{PO}_{4}-200.2 ; \quad 3 \mathrm{MgCO}_{3}$, $\mathrm{Mg}(\mathrm{OH})_{2 .} 3 \mathrm{H}_{2} \mathrm{O}-38.8 ; \mathrm{FeC}_{6} \mathrm{H}_{5} \mathrm{O}_{7} .5 \mathrm{H}_{2} \mathrm{O}-40.0 ; \mathrm{CaCO}_{3}-512.4$; $\mathrm{KI}-0.8$; $\mathrm{NaF}-0.9$; $\mathrm{CuSO}_{4} .5 \mathrm{H}_{2} \mathrm{O}-1.4 ; \mathrm{MnSO}_{4}-0.4$ and $\mathrm{CONH}_{3}-$ 0.05 .

** $1 \mathrm{~kg}$ of vitamin mix contained thiamine mono nitrate, $3 \mathrm{~g}$; riboflavin, $3 \mathrm{~g}$; pyridoxine $\mathrm{HCl}, 3.5 \mathrm{~g}$; nicotinamide, $15 \mathrm{~g}$; d-calcium pantothenate, $8 \mathrm{~g}$; folic acid, $1 \mathrm{~g}$; d-biotin, $0.1 \mathrm{~g}$; cyanocobalamin, $5 \mathrm{mg}$; vitamin A acetate, $0.6 \mathrm{~g} ; \alpha$-tocopherol acetate, $25 \mathrm{~g}$ and choline chloride, $10 \mathrm{~g}$. 
Collagen-linked fluorescence was measured by the method of Monnier et al. [17]. About $5 \mathrm{~g}$ of fresh skin tissue was minced in phosphate buffered saline (PBS, $10 \mathrm{mM}, \mathrm{pH}$ 7.4) and washed successively with $\mathrm{CM}$ mixture and N-2hydroxyethylpiperazine $\mathrm{N}$-2-ethane sulphonic acid (HEPES) buffer (0.02 M, pH7.5). The pellet was suspended in HEPES buffer containing 120 units of type VII collagenase and digested at $37^{\circ} \mathrm{C}$ for $48 \mathrm{~h}$ and centrifuged. The fluorescence of supernatant was measured at $440 \mathrm{~nm}$ excitation and $370 \mathrm{~nm}$ emission.

The solubility pattern was determined by the method of Miller and Rhodes [18]. Skin tissue (5 g) was extracted with neutral salt solvent containing $20 \mathrm{mM}$ ethylene diamine tetra acetic acid and $2 \mathrm{mM}$ N-ethyl maleimide. Extraction was repeated once more and the supernatants were pooled. The residue obtained was again extracted twice with $0.5 \mathrm{M}$ acetic acid. The resulting supernatants were pooled and the residue obtained was extracted with pepsin (100 mg/g wet tissue) and supernatants were collected. Hydroxyproline assay was done in the pooled supernatants [16].

The procedure of Adam et al. [19] was followed to assess the susceptibility of insoluble collagen to denaturing agents such as urea and potassium thiocyanate (KCNS). Insoluble collagen was suspended in $6 \mathrm{M}$ urea and $2 \mathrm{M}$ KCNS separately for 24 hours and then centrifuged. The supernatants were analyzed for hydroxyproline content.

Aldehyde content in collagen samples were analysed according to the method of Paz et al. [20] and expressed as $\mu \mathrm{mol}$ acetaldehyde/100 mg collagen. The level of thiobarbituric acid reactive substances was also measured by the method of Iqbal et al. [21]. The shrinkage temperature of collagen was determined as described by Nutting and Borasky [22].

For performing gel electrophoresis, collagen was extracted from skin by the method of Chandrakasan et al. [23]. The skin was dissected free, removed of hairs and washed in ice-cold
PBS. The following procedure was carried out at $0^{\circ} \mathrm{C}$. About 150-200 $\mathrm{g}$ of skin tissue was defatted with CM mixture and then extracted with $0.5 \mathrm{M}$ acetic acid overnight and centrifuged. The supernatant was precipitated with the addition of solid sodium chloride $(\mathrm{NaCl})$ to reach a concentration of $5 \%$ (W/V and kept overnight). The pellet obtained was suspended in $0.5 \mathrm{M}$ acetic acid containing $100 \mathrm{mg}$ pepsin/g wet tissue, centrifuged and the supernatant was precipitated with $\mathrm{NaCl}$. The solution was then centrifuged and the precipitate obtained was dissolved in $0.5 \mathrm{M}$ acetic acid and dialyzed overnight against $0.02 \mathrm{M}$ disodium hydrogen orthophosphate for at least 5-6 changes. The purified collagen was lyophilized and subjected to sodium dodecyl sulphate gel (SDS) electrophoresis for quantification of $\alpha$ and $\beta$ components using a 3\% stacking gel and a 5\% running gel. Coomassie brilliant blue was used for staining. The gels were scanned with a densitometer and $\alpha / \beta$ ratio of acid and pepsin-soluble collagen was calculated.

\section{STATISTICAL ANALYSES}

Values are expressed as means \pm S.D. Data within the groups were analysed using one-way analysis of variance (ANOVA) followed by Duncan's Multiple Range Test (DMRT). A value of $\mathrm{P}<0.05$ was considered statistically significant.

\section{RESULTS}

Daily food consumption was similar in the experimental groups and no significant alterations in the weight gain of animals were observed between the groups. (Final body weight: CON-174.0 g \pm 5.62; FRU-178.0 $\mathrm{g} \pm$ 5.43; FRU+LA$185.0 \mathrm{~g} \pm 3.76$; CON+LA-185.0 $\mathrm{g} \pm 4.47$ ).

Table 2 gives the levels of plasma glucose, insulin, fructosamine and glycated protein, $\mathrm{HbA}_{1} \mathrm{C}$ and the contents of hydroxyproline and total collagen in skin of control and

TABLE 2

Levels of glucose, insulin, fructosamine, glycated protein in plasma, glycated hemoglobin in blood and hydroxyproline and collagen content in skin of control and experimental animals

\begin{tabular}{lcccc}
\hline & CON & FRU & FRU+LA & CON+LA \\
\hline Glucose $(\mathrm{mmol} / \mathrm{L})$ & $4.7 \pm 0.5$ & $5.4 \pm 0.1^{*}$ & $4.9 \pm 0.1^{\#}$ & $4.8 \pm 0.1$ \\
Insulin $(\mu \mathrm{U} / \mathrm{ml})$ & $43.9 \pm 3.3$ & $80.9 \pm 5.2^{*}$ & $46.6 \pm 4.2^{\#}$ & $43.1 \pm 1.5$ \\
Fructosamine $(\mathrm{mmol} / \mathrm{L})$ & $0.84 \pm 0.06$ & $1.36 \pm 0.28^{*}$ & $0.93 \pm 0.06^{\#}$ & $0.86 \pm 0.02$ \\
Glycated protein $(\mu \mathrm{mol} / \mathrm{L})$ & $2.26 \pm 0.21$ & $3.44 \pm 0.25^{*}$ & $2.37 \pm 0.36^{\#}$ & $2.27 \pm 0.15$ \\
Glycated hemoglobin $(\%$ total $\mathrm{Hb})$ & $1.24 \pm 0.07$ & $3.63 \pm 0.09^{*}$ & $2.01 \pm 0.03^{\#}$ & $1.25 \pm 0.04$ \\
Hydroxyproline $(\mathrm{mg} / 100 \mathrm{mg}$ tissue $)$ & $6.04 \pm 0.49$ & $7.62 \pm 0.58^{*}$ & $6.47 \pm 0.58^{\#}$ & $6.41 \pm 0.55$ \\
Total collagen $(\mathrm{mg} / 100 \mathrm{mg}$ tissue $)$ & $48.61 \pm 3.58$ & $59.20 \pm 2.62^{*}$ & $48.69 \pm 2.96^{\#}$ & $45.72 \pm 2.75$ \\
\hline
\end{tabular}

Values are mean \pm SD of 6 rats from each group.

*Compared with CON $(P<0.05)$; ${ }^{*}$ Compared with FRU $(P<0.05)$.

ANOVA followed by DMRT.

CON-control, FRU-fructose, FRU+LA-fructose+lipoic acid, CON+LA- control+lipoic acid. 
TABLE 3

Extent of glycation and AGE formation, levels of aldehyde, lipid peroxidation, and shrinkage temperature in skin collagen of control and experimental animals

\begin{tabular}{lrrrc}
\hline & \multicolumn{1}{c}{ CON } & FRU & FRU+LA & CON+LA \\
\hline Glycation $(\mu \mathrm{g}$ glucose/mg collagen) & $7.91 \pm 1.06$ & $14.60 \pm 0.54^{*}$ & $8.67 \pm 0.87^{\#}$ & $7.96 \pm 0.98$ \\
Fluorescence (AU/ $\mu$ mol hydroxyproline) & $35.47 \pm 2.23$ & $40.40 \pm 1.99^{*}$ & $39.18 \pm 3.17^{\#}$ & $35.37 \pm 10.09$ \\
Aldehyde content $(\mu \mathrm{mol}$ acetaldehyde/100 mg collagen $)$ & $7.81 \pm 0.88$ & $14.93 \pm 1.61^{*}$ & $9.43 \pm 1.02^{\#}$ & $8.39 \pm 0.89$ \\
Lipid peroxidation $(\mathrm{nmol} / \mathrm{mg}$ protein) & $7.65 \pm 0.58$ & $14.77 \pm 0.48^{*}$ & $8.98 \pm 0.52^{\#}$ & $8.28 \pm 0.31$ \\
Shrinkage temperature $\left({ }^{\circ} \mathrm{C}\right)$ & $60.69 \pm 1.14$ & $66.44 \pm 1.60^{*}$ & $61.67 \pm 0.69^{\#}$ & $60.99 \pm 1.36$ \\
\hline
\end{tabular}

Values are means \pm SD from 6 animals in each group.

*compared with CON, P $<0.05$; ${ }^{*}$ compared with FRU, $\mathrm{P}<0.05$.

ANOVA followed by DMRT.

CON-control, FRU-fructose, FRU+LA-fructose+lipoic acid, CON+LA- control+lipoic acid.

experimental animals. The levels were significantly elevated in fructose-fed rats as compared to control rats. Fructose-fed rats treated with LA showed near-normal levels of these parameters.

Table 3 summarizes the effect of LA on the extent of glycation, AGE linked fluorescence, aldehyde content, peroxidation and shrinkage temperature in collagen obtained from skin of control and experimental rats. The rats fed fructose diet showed increased levels of these parameters as compared to rats fed control diet. LA treatment to fructose-treated rats restored the levels to normal control values.

Table 4 shows the subunit ratio $(\alpha / \beta)$ of acid and pepsin soluble skin collagen in control and experimental rats. Rats fed fructose showed a significantly decreased ratio as compared to control rats. But fructose-fed rats treated with LA showed near normal levels. The ratio was unaltered in control rats treated with LA.

Figures 1 and 2 show the solubility pattern of collagen in control and experimental animals. Rats fed fructose showed decreased solubility of collagen in neutral salt and acid and an increased solubility with pepsin. LA-treated fructose rats showed improved solubility with neutral salt and acid as compared to fructose-fed rats. Fructose rats showed poor solubility of collagen in the presence of denaturing agents (Figure 2).

Figures 3 shows the SDS-gel pattern of acid soluble and pepsin soluble collagen in skin of control and experimental rats. Fructose treated rat showed increased band width of different subunits of type I collagen and type III collagen, while fructose-treated LA supplemented rat showed a pattern similar to that of control rat. The lowest $\alpha / \beta$ ratio 1.11 (acid) and 1.68 (pepsin) was observed in the collagen from fructose-fed rat while collagen from the control rat showed the highest ratio of 1.58 and 2.50 , respectively. LA treated fructose rat showed significantly higher values as compared to fructose-treated rat.

\section{DISCUSSION}

Fructose feeding induced a significant increase in total collagen content and AGE-related fluorescence of skin collagen. Excessive collagen can result from an imbalance between its synthesis and degradation by interstitial collagenases. Long-term fructose feeding for a year in rats increased plasma fructosamine

TABLE 4

Effect of LA on the $\alpha / \beta$ ratio of acid- and pepsin-soluble collagen in skin of control and experimental animals

\begin{tabular}{lcccccc}
\hline & \multicolumn{2}{c}{$\begin{array}{c}\text { Acid soluble collagen } \\
\text { (Percentage of total collagen) }\end{array}$} & & \multicolumn{3}{c}{$\begin{array}{c}\text { Pepsin soluble collagen } \\
\text { (Percentage of total collagen) }\end{array}$} \\
\cline { 2 - 7 } & $\alpha$ & $\beta$ & $\alpha / \beta$ ratio & $\alpha$ & $\beta$ & $\alpha / \beta$ ratio \\
\hline CON & 60.5 & 38.2 & 1.58 & 69.8 & 27.9 & 2.50 \\
FRU & 52.7 & 47.2 & $1.11^{*}$ & 62.7 & 37.2 & $1.68^{*}$ \\
FRU+LA & 59.6 & 40.2 & $1.48^{\#}$ & 68.9 & 31.8 & $2.17^{\#}$ \\
CON+LA & 59.6 & 37.6 & 1.58 & 70.6 & 29.4 & 2.41 \\
\hline
\end{tabular}

Values are means \pm SD from 6 animals in each group.

*compared with CON, P $<0.05$; " compared with FRU, $\mathrm{P}<0.05$.

ANOVA followed by DMRT.

CON-control, FRU-fructose, FRU+LA-fructose+lipoic acid, CON+LA-control+lipoic acid. 

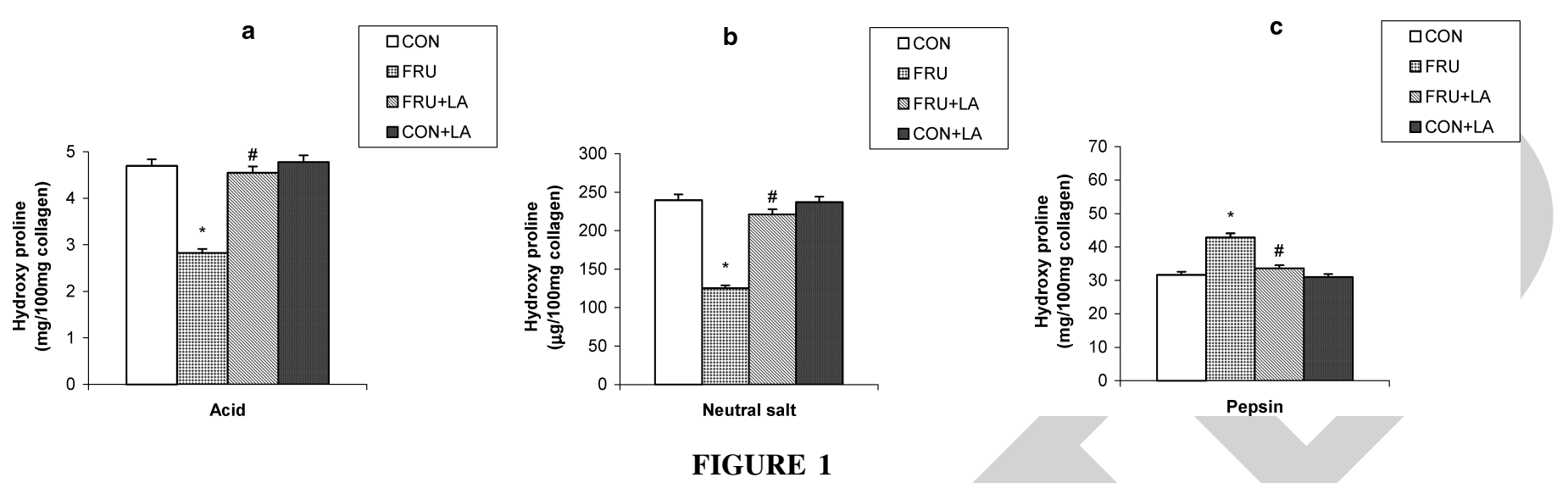

FIGURE 1

a) Neutral salt soluble collagen in skin. ${ }^{*}$ Compared with CON $(P<0.05)$; ${ }^{\#}$ Compared with FRU $(P<0.05)$ (one way ANOVA followed by DMRT). CON-control, FRU-fructose, FRU+LA-fructose+lipoic acid, CON+LA- control+lipoic acid.

b) Acid soluble collagen in skin. ${ }^{*}$ Compared with CON $(P<0.05)$; ${ }^{\#}$ Compared with FRU $(P<0.05)$ (one way ANOVA followed by DMRT). CON-control, FRU-fructose, FRU+LA-fructose+lipoic acid, CON+LA-control+lipoic acid. c) Pepsin soluble collagen in skin. ${ }^{*}$ Compared with CON $(P<0.05)$; ${ }^{\#}$ Compared with FRU $(P<0.05)$ (one way ANOVA followed by DMRT). CON-control, FRU-fructose, FRU+LA-fructose+lipoic acid, CON+LA-control+lipoic acid.

and $\mathrm{HbA}_{1} \mathrm{C}$, induced skin collagen crosslinking, altered the solubility of collagen and increased bone collagen fluorescence [10]. Prolonged fructose feeding thus accelerates aging by causing changes in age-related markers in collagen of skin and bones. In the present study the rats fed fructose for 45 days showed increased levels of glucose, insulin, fructosamine and glycated protein in plasma, $\mathrm{HbA}_{1} \mathrm{C}$ in blood and collagen glycation in skin.
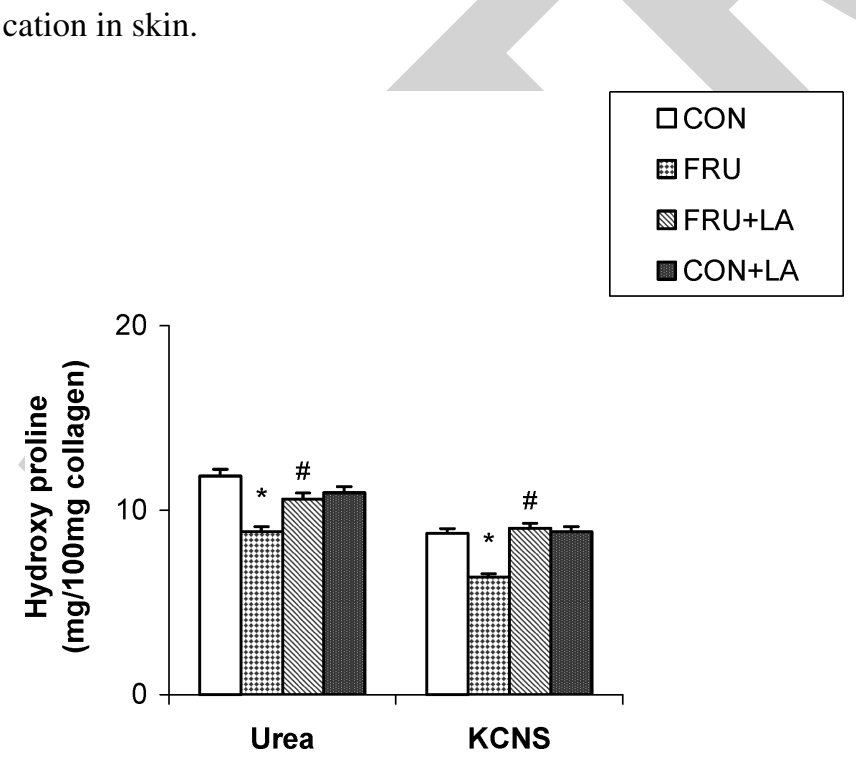

FIGURE 2

Susceptibility of skin collagen to denaturing agents. ${ }^{*}$ Compared with CON $(P<0.05)$; ${ }^{\#}$ Compared with FRU $(P<0.05)$ (one way ANOVA followed by DMRT).

CON-control, FRU-fructose, FRU+LA-fructose+lipoic acid, CON+LA-control+lipoic acid.
Alterations in physicochemical properties indicate extensive crosslinking and maturation of collagen in fructose-fed rats. Excessive covalent cross links in collagen fibres and changes in the content of imino acids such as proline and hydroxyproline can increase the shrinkage temperature [24] and alter the solubility pattern [25]. The percentage solubility of collagen in neutral salt and acid were significantly reduced, while there was an increase in pepsin solubility of collagen from fructose-fed rats. The structure and properties of collagen are modified due to extensive crosslinking and have been reported in aging and in various pathological conditions including diabetes [26].

A significant increase in peroxidation in collagen samples were observed in skin of fructose-fed rats. Malondialdehyde, an end product of lipid peroxidation can react with the free amino groups of collagen and stimulate cross-linking [27]. Previous reports from our laboratory [28, 29] and by others [30] have shown increased lipid peroxidation products in blood and tissues indicating oxidative stress in fructose-treated rats.

The SDS gel pattern of skin collagen in our present study confirms the increase in cross-linking of collagen in fructosefed rats. The band size of $\beta$-components of collagen in fructosefed rats was higher than that of control rats. The relative abundance of high molecular weight collagen chains is demonstrated by the ratio of $\alpha$ to $\beta$ chains. $\beta$ chains are dimers in which the inter chain cross links are not disulfide bridges [10]. Type III $\left(\alpha_{1}\right)$ fraction of collagen, which is specific for skin tissues are found to be significantly increased in fructose-fed rats as compared to that of control rats [10].

LA treatment prevented fructose-induced hyperglycemia and hyperinsulinemia and also abolished the alterations in 

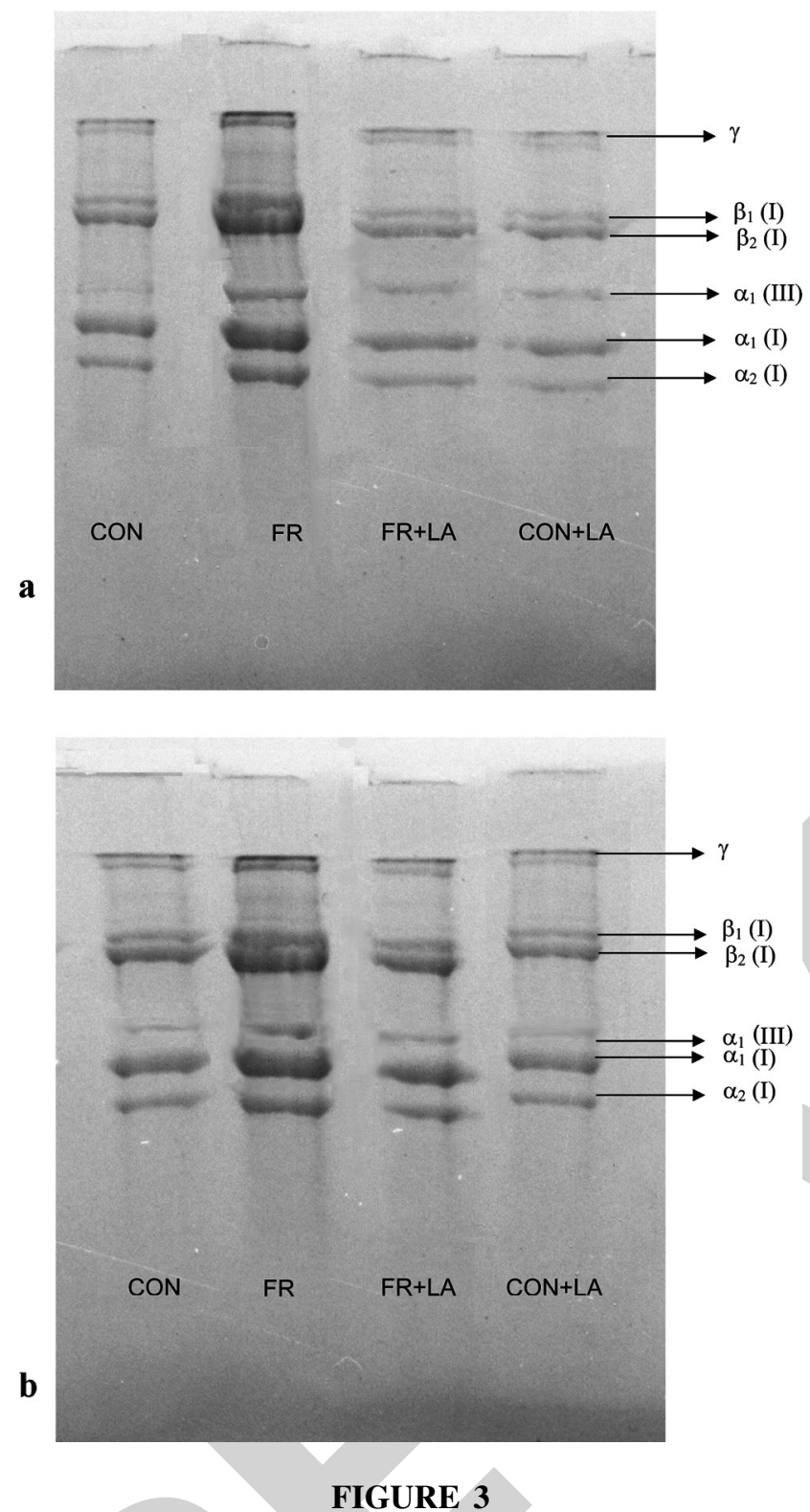

a) SDS gel pattern of acid soluble collagen from skin in normal and experimental rats. Compared with FRU $(P<0.05)$ (one way ANOVA followed by DMRT). CON-control, FRU-fructose, FRU+LA-fructose+lipoic acid, CON+LAcontrol+lipoic acid. b) SDS gel pattern of pepsin soluble collagen from skin in normal and experimental rats. Compared with FRU $(P<0.05)$ (one way ANOVA followed by DMRT). CON-control, FRU-fructose, FRU+LA- fructose+lipoic acid, $\mathrm{CON}+\mathrm{LA}$-control+lipoic acid.

collagen properties. Collagen from LA-administered fructosefed rats displayed decreased glycation, AGE formation, aldehyde and peroxide content in skin collagen, together with a decline in total collagen content as compared to untreated fructose-fed rats. The solubility pattern was improved with a relative increase in neutral salt and acid soluble collagen. These changes indicate the reduction in cross-linking of collagen in LA-treated rats.

The effects of LA could be due to the positive influence of LA on glycemia and glucose metabolism. LA treatment improves glucose utilisation in rat diaphragm [31]. LA has been reported to increase glucose uptake and disposal in muscle isolated from Zucker diabetic rats [32].

The antioxidant function of LA could also contribute to inhibition of protein glycation, AGE formation and cross-linking. The activity of prolyl hydroxylase an ascorbic acid-dependent enzyme has been reported to be altered in diabetic rats [33]. This enzyme is required to maintain the normal properties of collagen. This alteration is mainly due to the reduction in ascorbic acid concentrations. In a previous study, we reported a significant decrease in ascorbic acid concentration in plasma and tissues of fructose-fed rats and its reversal by LA at this dosage (35 mg/kg b.w) [28, 29]. LA effectively recycles ascorbic acid, $\alpha$-tocopherol and glutathione there by elevating their tissue levels. These endogenous antioxidants inhibit protein glycation and advanced glycation end product formation [34]. LA inhibits tissue lipid peroxidation in rats fed fructose [29] and protein glycation in RBCs exposed to high concentrations of glucose [35]. Crosslinking of corneal collagen by glucose in vitro is dependent on transition metal-catalyzed oxidation of glucose or Amadori products on collagen, requires oxygen, and involves the formation of superoxide, hydrogen peroxide, and hydroxyl radicals [36]. LA scavenges reactive oxygen species, chelates metal ions and participates in the repair of oxidized proteins [9]. We suggest that LA could prevent collagen abnormalities by a combination of its effect on glucose utilization and antioxidation.

Consumption of fructose in diet has increased in the general population in recent years. Crystalline fructose is used extensively as a sweetener in pharmaceuticals and in food industry. High fructose sweeteners in soft drinks is estimated to account for almost half of the total added sugars in the U.S. diet [37]. Long-term fructose consumption may provoke glycation and collagen crosslinking [10] and hence may contribute to diabetic complications.

LA administration delays the development of secondary complications and appears to be an useful ancillary treatment for diabetic complications $[38,39]$. LA is used in Germany to treat diabetes-related complications for over 30 years [40]. The results of the present study provide a mechanism for LA action in delaying diabetic complications and offer credentials for its use in the management of diabetic disease.

\section{REFERENCES}

[1] Gelse, K., Poschl, E., and Aigner, T. (2003) Collagens-structure, function and biosynthesis. Adv. Drug Del. Rev., 55, 15311546. 
[2] Prockop, D. J., and Kivirikko, K. I. (1995) Collagens: Molecular biology, diseases and potentials for therapy. Annual Rev. Biochem., 64, 403-434.

[3] Vlassara, H., Bucala, R., and Striker, L. (1994) Pathogenic effects of glycosylation: Biochemical, biologic and clinical implications for diabetes and ageing. J. Lab. Invest., 70, 138-151.

[4] Reiser K. M. (1998) Non-enzymatic glycation of collagen in ageing and diabetes. Proc. Soc. Biol. Med., 218, 23-37.

[5] Sims, T. J., Rasmussen, L. M., Oxlund, H., and Bailey, A. J. (1996) The role of glycation cross-links in diabetic vascular stiffening. Diabetologia, 39, 946-951.

[6] Sakata, N., Menj, J., Jimi, S., and Takebayashi, S. (1995) Non-enzymatic glycation and extractability of collagen in human atherosclerotic plaques. Atherosclerosis, 116, $63-75$.

[7] Brownlee, M., Cerami, A., and Vlassara, H. (1988) Advanced glycosylation end products in tissue and biochemical basis of diabetic complications. N. Engl. J. Med., 318, 1315-1321.

[8] Han, D., Handleman, G., Marcocci, L., et al. (1997) Lipoic acid increases de novo synthesis of cellular glutathione by improving cystine utilization. Biofactors, 6, 321-338.

[9] Packer, L., Witt, E. H., and Tritschler, H. J. (1995) $\alpha$-lipoic acid as a biological antioxidant. Free Rad. Biol. Med., 19, 227-250

[10] Levi, B., and Werman, M. J. (1998) Long-term fructose consumption accelerates glycation and several age-related variables. J. Nutr., 128, 1442-1449.

[11] Midoui, A. E., and De Champlain, J. (2002) Prevention of hypertension, insulin resistance and-oxidative stress by $\alpha$-lipoic acid. Hypertension, 39, 303-307.

[12] Vasdev, S., Ford, C. A., Parai, S., Longerich, L., and Gadag, V. (2000) Dietary lipoic acid supplementation prevents fructoseinduced hypertension in rats. Nutr. Metab. Cardiovasc. Dis., 10, 339-346.

[13] Sasaki, T., Matsui, S., and Sonae, A. (1972) Effect of acetic acid concentration on the colour reaction in the $o$-toluidineboric acid method for blood glucose estimation. Rinshokagaku, 1, 346-353.

[14] Johnson, R. N., Metealf, P. A., and Baker, J. R. (1983) Fructosamine: a new approach to the estimation of serum glycosylation. An index of diabetic control. Clin. Chim. Acta, 217, 87-95.

[15] Rao, P., and Pattabiraman, T. N. (1989) Reevaluation of the phenol sulphuric acid reaction for the estimation of hexoses and pentoses. Anal. Biochem., 181, 18-22.

[16] Woessner, J. F. (1961) The determination of hydroxyproline in tissue and protein samples containing small portions of this imino acid. Arch. Biochem. Biophy., 93, 440-447.

[17] Monnier, V. M., Vishwanath, V., Frank, K. E., Elmets, C. A., Dauchot, P., and Kohn, R. R. (1986) Relation between complications of type I diabetes mellitus and collgen-linked fluorescence. New Eng. J. Med., 314, 403-408.

[18] Miller, E. J., and Rhodes, R. K. (1982) Preparation and characterization of different types of collagen. Methods in Enzymol., 82, 33-64.

[19] Adam, M., Fietzek, P., and Kuhn, K. (1968) Investigations on the reaction of metals with collagen in vivo. The effect of bismuth, copper and mercury compounds. Eur. J. Biochem., 3, 415-418.
[20] Paz, M. A., Lent, R. W., Faris, B., Frazblan, C., Blumfeld, O. O., and Gallop, P. M. (1969) Aldehydes in native and denatured calf skin procollagen. Biochem. Biophys. Res. Commun., 34, 221-229.

[21] Iqbal, M., Sharma, S. D., Rezaza, Deh, H., Abdullia, M., Hassan, N., and Athar, M. (1996) Glutathione metabolizing enzymes and oxidative stress in Fe-NTA mediated liver injury. Redox Rep., 2, 385-391.

[22] Nutting, G. C., and Borasky, R. (1949) Microscopic methods for determining shrinkage temperature of collagen and leather. $J$. Amer. Leath. Chem. Assoc., 44, 831-839.

[23] Chandrakasan, G., Torchia, D. A., and Piez, K. A., (1976) Preparation of intact monomeric collagen from tail tendon and skin and the structure of the nonhelical ends in solution. J. Biol. Chem., 251, 6062-6067.

[24] Rao, C. N., Rao, V. H., and Sanjeevi, R. (1981) Effect of bioflavonoids on the mechanical and thermal properties of skin and tendon. Ind. J. of Biochem. Biophys., 18, 224-228.

[25] Meng, J., Sakata, N., Takebayashi, S., Asano, T., Futata, J., Araki, N., and Horachi, S. (1996) Advanced glycation end products of the Maillard reaction in aortic pepsin insoluble and pepsin soluble collagen form diabetic rats. Diabetes, 45, 1037-1043.

[26] Brinkman, J., Necsj, C. M., Gaber, Y., Sibhi, H., Notbuhn, H., Hunzelmann, N., Feitzek, P. P., and Muller, P. K. (2001) Different pattern of collagen crosslinks in two sclerotic skin diseases lipo dermatosclerosis and circumbscribed scleroderma. J. Invest. Dermatol., 117, 269-273.

[27] Fu, M. X., Raquena, J. R., Jenkins, A. J., Lyons, T. J., Baynes, J. W., and Thorpe, S. R. (1996) The advanced glycation end product, N-epsilon-(carboxy methyl lysine, is a product of both lipid peroxidation and glycoxidation reactions. J. Biol. Chem., 271, 9982-9986.

[28] Thirunavukkarasu, V., and Anuradha, C. V. (2004) Influence of $\alpha$ lipoic acid on lipid peroxidation and antioxidant defence system in blood of insulin-resistant rats. Diab. Obes. Metab., 6, 200-207.

[29] Thirunavukkarasu, V., Nandhini, A. T. A., and Anuradha, C. V. (2003) Lipoic acid restores antioxidant system in tissues of hyperinsulinemic rats. Ind. J. Med. Res., 118, 134-140.

[30] Faure, P., Rossini, E., Lafond, J. L., Richard, M. J., Favier, A., and Halimi, S. (1997) Vitamin E improves the free radical defense system potential and insulin sensitivity of rats fed high fructose diets. J. Nutr., 127, 103-107.

[31] Haugaard, N., and Haugaard, S. E. (1970) Stimulation of glucose utilization by thioctic acid in rat diaphragm incubated in vitro. Biochim. Biophys. Acta, 222, 583-586.

[32] Jacob, S., Henriksen, E. J., Tritschler, H. J., Augustin, H. J., and Dietze, G. J. (1996) Improvement of insulin-stimulated glucosedisposal in type 2 diabetes after repeated parentral administration of thioctic acid. Exp. Clin. Endocrinol. Diabetes, 104, 284-288.

[33] McLennan, S., Yue, D. K., Fisher, E., Capogreco, C., Heffernan, S., Ross, G. R., and Turtle, J. R. (1988) Deficiency of ascorbic acid in experimental diabetes. Relationship with collagen and polyol abnormalities. Diabetes, 37, 359-361.

[34] Vinson, A. J., and Howard, B. T. (1996) Inhibition of protein glycation and advanced glycation end products by ascorbic acid and other vitamins and nutrients. J. Nutr. Biochem., 7, 659663.

[35] Jain, S. K., and Lim, G. (2000) Lipoic acid decreases lipid peroxidation and protein glycosylation and increases $\left(\mathrm{Na}^{+} / \mathrm{K}^{+}\right)$and 
$\mathrm{Ca}^{+}$ATPases activities in high glucose-treated human erythrocytes. Free Rad. Biol. Med., 29, 1122-1128.

[36] Chace, K. V., Carubelli, R., and Nordquist, R. E. (1991) The role of non-enzymatic glycosylation, transition metals, and free radicals in the formation of collagen aggregates. Arch. Biochem. Biophy., 288, 473-480.

[37] Johnson, R. K., and Frary, C. (2001) Choose beverages and foods to moderate your intake of sugars: The 2000 dietary guidelines for Americans-what's all the fuss about. J. Nutr., 131, 2766S-27771S.
[38] Ametov, A. S., Barnov, A., Dyck, P. J. et al. (2003) The sensory symptoms of diabetic polyneuropathy are improved with $\alpha$-lipoic acid. Diab. Care, 26, 770-776.

[39] Melhem, M. F., Craven, P. A., DeRubertis, F. R. (2001) Effects of dietary supplementation of $\alpha$-lipoic acid on early glomerular injury in diabetes mellitus. J. Am. Soc. Nephrol., 12, 124-133.

[40] Ziegler, D., Hanfield, M., Ruhnau, K. J. et al. (1999) Treatment of symptomatic diabetic polyneuropathy with the antioxidant $\alpha$ lipoic acid. Diabetes Care, 22, 1296-1301. 